Abstract P219 Table 1 Risk data for patients attending the MSM clinic and routine GU clinic

\begin{tabular}{|c|c|c|c|c|c|c|c|}
\hline Patient group & $\begin{array}{l}\text { Number of partners } \\
\text { in the past } 3 \text { months }\end{array}$ & $\begin{array}{l}12 \text { or more partners } \\
\text { in the past } 3 \text { months }\end{array}$ & Group sex & Sex parties & Chem-sex & $\begin{array}{l}\text { Casual partner } \\
\text { sourcing online }\end{array}$ & $\begin{array}{l}\text { Sexual activity in } \\
\text { London }\end{array}$ \\
\hline \multirow[t]{2}{*}{ MSM clinic $(n=13)$} & Mean $=6.4$ & $15.4 \%$ & $38.5 \%$ & $23.1 \%$ & $30.8 \%$ & $100 \%$ & $53.8 \%$ \\
\hline & Mode $=4$ & & & & & & \\
\hline \multirow[t]{2}{*}{ GU clinic $(n=27)$} & Mean $=4.5$ & $7.4 \%$ & $37 \%$ & $11.1 \%$ & $14.8 \%$ & $70.4 \%$ & $22.2 \%$ \\
\hline & Mode $=2$ & & & & & & \\
\hline$p$ value & & $p=0.392$ & $p=0.599$ & $p=0.293$ & $p=0.211$ & $p=0.029$ & $p=0.021$ \\
\hline $\begin{array}{l}\text { Reason for attending } \\
\text { MSM clinic }\end{array}$ & Less stigma & STI screen & Tailored service & Advice and support & Rapid HIV test & & \\
\hline $\begin{array}{l}\text { Total number of } \\
\text { responses }\end{array}$ & 3 & 4 & 5 & 6 & 6 & & \\
\hline
\end{tabular}

standard deviation 11.48). Patients from both groups were involved in all behaviours, however MSM clinic patients were more likely to engage in risky sexual activity in London $(\mathrm{p}=$ $0.021)$ and source casual partners online $(p=0.029)$ compared to the $\mathrm{GU}$ clinic population.

Discussion/conclusion The MSM clinic attracted a population with riskier sexual behaviours. Patients cited non-judgemental acceptance and understanding of MSM sexual practices as pivotal for attending. Perceived reduction in stigma, rapid HIV testing and tailored advice has encouraged service engagement; this provides a valuable opportunity to screen and vaccinate patients at high risk of sexually transmitted infections.

\section{P220 EXPANDING SEXUAL HEALTH OUTREACH PROVISION FOR SEX WORKERS IN THE COMMUNITY}

Christine Vivian*, Jonathan Roberts, Kathir Yoganathan, Jean Beard. Abertawe Bro Morgannwg, Swansea, USA

\subsection{6/sextrans-2015-052126.264}

Background/introduction Isolation of six consecutive cases of gonorrhoea amongst sex workers (SW) in 2012 led to a multiagency review of sexual health provision for this hard to reach group. It identified reluctance to access traditional integrated sexual health services in the area, so a more extensive community based outreach approach was implemented.

Aim(s)/objectives To observe the uptake of sexual health screening and contraception in the community amongst SW.

Methods Case note review of all SW seen in the community by the sexual health outreach nurse from July 2013 to January 2015.

Results 99 SWs were seen during the study period. Median age 26(range 17 to 50), 95 were female with the majority identifying as white UK (65). 73 worked exclusively in sex parlours. 12 STIs were diagnosed amongst $98 \mathrm{SW}$ screened. Of the 22 current IVDUs 11 tested positive to Hepatitis C whilst 3 were already known to have the infection. 96 SWs had used one or more forms of contraception prior to consultation including 92 who used condoms. Of female SW 22 commenced or continued injectable contraception and cervical cytology was performed on 18. Uptake of Hep B vaccination was consistent (73) with 24 already vaccinated or known to be Hep B immune.

Discussion/conclusion Partnership working enhanced referral pathways, making access to sexual health screening easier for this hard to reach group. An increased uptake of STI screening, contraception and detecting untreated infections demonstrates that a flexible and opportunistic approach is beneficial for this client group.

\section{P221 DRUG AND ALCOHOL MISUSE IS ASSOCIATED WITH STIS IN MEN WHO HAVE SEX WITH MEN (MSM)}

${ }^{1}$ Waseem Rawdah*, 'Larissa Mulka, ${ }^{1}$ Elaney Youssef, ${ }^{2}$ Ben Tooke, 'Daniel Richardson. ${ }^{1}$ Claude Nicol Centre, Royal Sussex County Hospital, Brighton, UK; ${ }^{2}$ Terrence Higgins Trust, Brighton, UK

\subsection{6/sextrans-2015-052126.265}

Background/introduction Alcohol and recreational drug misuse is an increasing problem in sexual health clinics, particularly MSM where it is often associated with unsafe sexual practices and increasing prevalence of sexually transmitted infections (STIs).

Aims/objectives To determine the proportion of MSM testing positive for STIs reporting substance misuse in a dedicated sexual health clinic, compared to the proportion attending THT services reporting high risk sexual activity requiring support for substance misuse.

Methods Case notes of patients attending a MSM clinic testing positive for STIs over a 6 month period were reviewed. Data was collected on type of STI, recreational drug and alcohol use. Over the same period, data on high-risk sexual activity and referral to specialist drug and alcohol services was collected for MSM attending THT services.

Results 285 MSM attended the sexual health clinic, whereby 97 (34\%) tested positive for 1 or more STI. 88 cases of gonorrhoea were seen, 49 cases of chlamydia, 20 cases of syphilis and 7 new HIV infections. Of those testing positive for STIs, 45 (46\%) reported alcohol and/or recreational drug misuse. Of the 162 MSM attending THT services, 90 (56\%) reported high risk sexual behaviour with concurrent substance misuse. $27(30 \%)$ were referred to specialist substance misuse services.

Discussion/conclusions High rates of substance misuse associated with high risk sexual activity were seen in the MSM clinic and at THT. This reinforces the importance of screening and brief intervention/referral for substance misuse as a risk reduction strategy for STIs and HIV.

\section{P222 MULTIDISCIPLINARY AND MULTIAGENCY WORKING IN A METROPOLITAN YOUNG PEOPLE'S SEXUAL HEALTH CLINIC}

Nasiha Lindner, Katrina Strachan, Mahasti Darvishijazi, Alisa Richardson-Jones, Petal Edwards, David Phillips, Mark Pakianathan*. Croydon University Hospital, London, UK

\subsection{6/sextrans-2015-052126.266}

Background/introduction A weekly multidisciplinary team meeting (MDTM) was introduced to discuss clinically or 
psychosocially complex cases, facilitate multiagency (MA) working and ensure safeguarding of vulnerable young people accessing services.

Aim(s)/objectives To describe characteristics of young people accessing the service and compare those warranting MDTM or MA input to those in whom this was not required.

Methods Retrospective review of electronic patient records of new patients accessing a young people's clinic ( $\leq 18$ years) from January to June 2014. Demographics, clinical and psychosocial details, MDTM case note entries or liaison with other agencies including social services, voluntary sector, mental and other health were analysed. Significance calculation: fisher's exact test. Results 159 cases reviewed. Median age 16 years: female 80\%, locally resident $80 \%$, self-referral $77 \%$, white British $22 \%$, black Caribbean 22\%. 67(42\%) required MA/MDTM working. (45\%, $\mathrm{n}=30 \mathrm{had}$ MA referral/liaison). MA/MDTM patients were more likely to have health adviser input: $57 \%$ vs $21 \% \mathrm{p}=$ 0.0001 , report mental health problems: $33 \%$ vs $3 \% \mathrm{p}=0.0001$, have a social worker: $27 \%$ vs $7 \% \mathrm{p}=0.0003$ or if female, not on contraception: $60 \%$ vs $39 \% \mathrm{p}=0.005$. Amongst those requiring MA/MDTM input $12 \%(\mathrm{n}=8)$ had a safeguarding concern and $7 \%(\mathrm{n}=5)$ were identified as at risk of sexual exploitation.

Discussion/conclusion MDTMs effectively enabled discussion of complex patients. MDTM/MA working was common and such cases were more likely to: lack contraception, need health adviser input, have a social worker and mental health problems highlighting an opportunity for closer working with mental health services.

\section{P223 UNDERSTANDING THE GREATER BURDEN OF STIS AMONG BLACK CARIBBEANS IN THE UK: EVIDENCE FROM A SYSTEMATIC REVIEW}

${ }^{1}$ Sonali Wayal*, ${ }^{1}$ Catherine Griffiths, ${ }^{1}$ Catherine Mercer, ${ }^{1}$ Makeda Gerressu, ${ }^{2}$ Gwenda Hughes. 'University College London, London, UK; ${ }^{2}$ Public Health England, London, UK

10.1136/sextrans-2015-052126.267

Background In the UK, Black Caribbeans are disproportionately affected by STIs.

Aim We conducted a systematic review of attitudinal, behavioural and contextual risk factors of this inequality.

Methods Ten electronic databases were searched for studies on risk factors and drivers of STI among UK Black Caribbeans from 1948 to 30/11/2014. Two independent reviewers screened all identified abstracts and extracted data from selected studies using standardised forms.

Results Of 3220 abstracts identified, 165 were included in the review. STI risk among Black Caribbeans is higher compared to other ethnic groups and varies by gender and age. Being single and reporting first intercourse aged $<16,>1$ new sex partner in the past year, concurrency, and assortative sexual mixing were identified as risk factors. STIs were considered of lower priority than HIV/unplanned pregnancy. Barriers to condom use, especially among women with older and regular partners, were reported. Compared to other ethnic groups, Black Caribbeans were more likely to have ever attended a STI clinic and tested for HIV, but Black Caribbean women were more likely to report delays in seeking care and be sexually active whilst symptomatic. Perceived negative attitudes of clinic staff of the same ethnicity towards young women negatively affected care-seeking.

Discussion/conclusion Sexual behavioural risk factors or access to care did not fully explain the disproportionate STIs burden among Black Caribbeans highlighting the need for further evidence on contextual drivers of STIs. STI reduction interventions should be gender-specific, informed by partnership patterns and address attitudes to STIs and sexual health care-seeking.

\section{P224 THE SEXUAL HEALTH OF THE HOMELESS - AN OUTREACH SEXUAL HEALTH SCREENING PROJECT}

${ }^{1}$ Sarah Stockwell*, ${ }^{1}$ Gillian Dean, ${ }^{2}$ Travis Cox, ${ }^{2}$ Marc Tweed, ${ }^{3}$ Jane Poole, ${ }^{4}$ Georgina Hume, ${ }^{4}$ Steven Nicolson, ${ }^{4}$ Laura Hutchinson. ${ }^{1}$ Brighton and Sussex University Hospitals NHS Trust, Brighton, UK; ${ }^{2}$ Terrance Higgins Trust, Brighton, UK; ${ }^{3}$ Oasis Project, Brighton, UK; ${ }^{4}$ Chlamydia Screening Project, Brighton, UK

\subsection{6/sextrans-2015-052126.268}

Background/introduction Homeless people are at increased risk of STIs, and may struggle to attend conventional services. To improve sexual health access and knowledge for this group, THT launched a weekly outreach testing project for asymptomatic clients in June 2014 at the local homeless service. HIV point of care tests (POCT) and self-taken STI screens (SHS) were offered. Hepatitis $\mathrm{B} / \mathrm{C}$ POCTs were introduced more recently.

Aim(s)/objectives To assess the value of the outreach service and describe project outcomes.

Methods User demographics and testing outcomes were collected at each attendance and reviewed at 6 months.

Results From June to December 2014, 129 clients presented. $83 \%$ were white British, 92\% were male. The mean age was 36 (range 19-65 years). 84\% identified as heterosexual, 14\% bisexual and 2\% homosexual. Only 26\% had previously tested for HIV. Of the asymptomatic service users, $45 \%$ had a HIV test (all negative) and $23 \%$ had a self-taken SHS. Two cases were positive; one urethral chlamydia, one rectal gonorrhoea. Eighteen referrals were made to the local $\mathrm{SH}$ clinic for symptomatic screens, blood-borne virus (BBV) testing, vaccination and contraception. Since introducing hepatitis POCTs 2 weeks ago, 4 clients have tested and 2 were positive for hepatitis C.

Discussion/conclusion Prior to project launch, this client group had significant anxiety regarding HIV and BBV. Having the ability to access a full SH screen in familiar surroundings was welcomed. A significant number of infections have been identified demonstrating the importance of the outreach project, and the need for strong links with mainstream services.

\section{P225 REACH OUT AND TEST ME}

${ }^{1}$ Susanna Currie*, ${ }^{2}$ Melissa Pearson, ${ }^{2}$ Holly Eadsforth, ${ }^{1}$ Orla McQuillan. ${ }^{1}$ Manchester Royal Infirmary, Manchester, UK; ${ }^{2}$ University of Manchester, Manchester, UK

\subsection{6/sextrans-2015-052126.269}

Background Saunas have traditionally been where MSM participate in risky sexual activities, contracting high numbers of sexually transmitted infections (STIs) and have been ideal targets for sexual health outreach work. There has however been a recent trend towards private "Chem-Sex "parties arranged through social media. Is sexual health outreach work in the saunas still justified, particularly in these financially pressured times?

Aim Comparison of outreach services in a large urban centre in 2011 and 2013.

Methods Retrospective case-note review of patients who accessed outreach services July-December 2011 and 2013. 